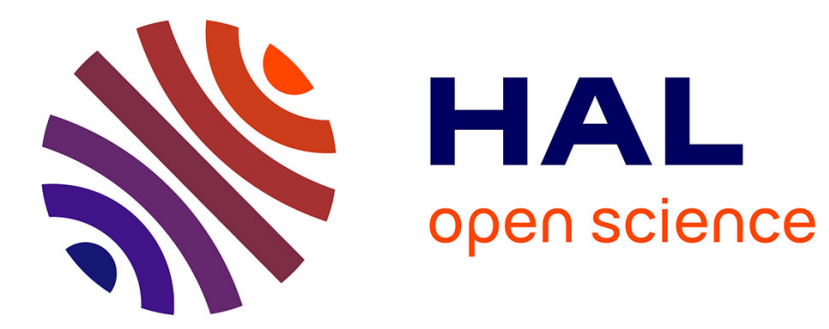

\title{
Development of a Smart Assembly Data Model
}

Luiz Durão, Sebastian Haag, Reiner Anderl, Klaus Schützer, Eduardo Zancul

\section{To cite this version:}

Luiz Durão, Sebastian Haag, Reiner Anderl, Klaus Schützer, Eduardo Zancul. Development of a Smart Assembly Data Model. 14th IFIP International Conference on Product Lifecycle Management (PLM), Jul 2017, Seville, Spain. pp.655-666, 10.1007/978-3-319-72905-3_58 . hal-01764193

\section{HAL Id: hal-01764193 \\ https://hal.inria.fr/hal-01764193}

Submitted on 11 Apr 2018

HAL is a multi-disciplinary open access archive for the deposit and dissemination of scientific research documents, whether they are published or not. The documents may come from teaching and research institutions in France or abroad, or from public or private research centers.
L'archive ouverte pluridisciplinaire HAL, est destinée au dépôt et à la diffusion de documents scientifiques de niveau recherche, publiés ou non, émanant des établissements d'enseignement et de recherche français ou étrangers, des laboratoires publics ou privés. 


\title{
Development of a Smart Assembly Data Model
}

\author{
Luiz Fernando C. S. Durão ${ }^{1}$, Sebastian $\mathrm{Haag}^{2}$, Reiner Anderl ${ }^{2}$, Klaus Schützer ${ }^{3}$, \\ Eduardo Zancul ${ }^{1} *$ \\ ${ }^{1}$ University of São Paulo, Brazil \\ luiz.durao@usp.br \\ ezancul@usp.br \\ ${ }^{2}$ Technische Universität Darmstadt, Germany \\ haag@dik.tu-darmstadt.de \\ anderl@dik.tu-darmstadt.de \\ ${ }^{3}$ Methodist University of Piracicaba, Brazil \\ schuetzer@scpm.unimep.br \\ * to whom correspondence should be addressed
}

\begin{abstract}
Current technological advances pave the way for highly flexible production processes within Cyber-Physical Production Systems (CPPS). In a CPPS, every component being produced may be represented by a virtual data model containing its own unique information. Components are also information carriers with communication features enabled by an Internet-based exchange of information. The exchange of information between components and with the production system may happen over the whole manufacturing process. The availability of detailed information about every component supports the implementation of optimized assembly processes, called Smart Assembly of smart components. Smart Assembly is an approach to assembling different components according to unique specifications of every product variant, and considering the most efficient combination of components for each assembly. Therefore, a structured component data model considering data storage and data access is needed. However, for the Smart Assembly of smart components, the underlying data structure and processes have to be developed. The objective of this paper is to propose a data structure to enable the Smart Assembly of components in an assemble-to-order production scenario. To achieve the proposed objective, two use cases have been developed to simulate the Smart Assembly of smart components.
\end{abstract}

Keywords: Smart Assembly; Smart components; Industrie 4.0. 


\section{Introduction}

Current market trends indicate increasing demand for tailor-made products and solutions, with reduced delivery times [1]. The manufacturing process in this scenario involves dealing with a great variety of products [2]. Each client provides unique information so that the product can be tailored to its requirements, challenging the assumptions of traditional mass production [3] [4]. The increase in product variety, provided by the individualized products, may decrease internal operation performance [2] [5]. A major issue for the industry is to offer customized products without substantial impact on final costs both at the manufacturing and distribution of the products [2]. Therefore, new approaches and solutions are required for manufacturing and assembly.

The assembly process is one of the most relevant steps to high product variety [6] [7]. Several approaches, methodologies and techniques have been researched and developed over the years for manufacturing assembly process planning. The historical development of assembly can be organized into three main phases: (i) manual assembly; (ii) line assembly, introduced by Ford; (iii) flexible, semi-automated assembly. More recently, the assembly process has been impacted by new technologies related to process control, information technology, and networking leading to what can be called Smart Assembly. A more agile and responsive assembly process strategy has to be developed to increase the efficiency of the process [7].

Internet technologies, information exchange and communication between people, products, machines, and resources are applied to a networked environment of physical objects and their virtual representation, resulting in an Internet of Things [8] - as considered by the initiative Industrie 4.0. These technologies and elements may be the key to create a Smart Assembly process. However, the amount of data generated during production and assembly in a connected environment requires a proper data structure to collect and process the information correctly.

The objective of this paper is to propose an initial data structure to enable the Smart Assembly of components in a manufacturing scenario. The scenario has been implemented in two use cases representing a regular assembly process, and a Smart Assembly process. These use cases simulate an Internet-based collaboration between the central factory and a distributed production site located respectively in Germany and Brazil.

The paper is structured in five sections. After the introduction of the research topic in Section 1, Section 2 provides a state of the art literature review. In Section 3, the research approach is presented. Section 4 contains a detailed scenario description, discussing the most important technical aspects and testing procedures. The conclusion and an outlook on further research needs are discussed in Section 5. 


\section{Data Model Requirements - Literature Review}

In this section, the state of the art concerning Industrie 4.0 (Section 2.1), assembly process (Section 2.2), and Smart Assembly (Section 2.3) are presented.

\subsection{Industrie 4.0}

The term "Industrial Revolution" refers to a profound change not only in the manufacturing methods and tools, but also on the way that society interacts with the manufacturing systems [9].

In the first industrial revolution, manufacturing was mechanized by steam power. In the second, production was marked by electrification and division of labor. Starting from the 1970s up to now, the third industrial revolution has been characterized by rapid advancements in Information Technology (IT), including automated manufacturing processes [8]. The adoption of Advanced Manufacturing Technology in connected environments, creating smart factories, is currently triggering a new industrial revolution (called fourth industrial revolution or Industrie 4.0) enabling the integration of information from various sources, and the production of items that are more complex, in reduced time [8].

Advanced Manufacturing Technologies (AMT) are computer assisted technologies used by industrial companies to produce their products [10] [11]. The term AMT can be described as a group of technologies used to monitor and control manufacturing activities (e.g. storing and handling data). Considering that the assembly process may represent up to $50 \%$ of total production time, the adoption of AMT in the assembly may considerable increase efficiency and efficacy [7][12][13].

Modern and reconfigurable manufacturing systems, as proposed by Industrie 4.0, facilitate complex assembly processes, enabling the communication and matching of components in a smart environment [14].

\subsection{Assembly Process}

Assembly process is the process of connecting components or subsets of components to form a more complex end-product [7].

A proper assembly process can increase product quality, decrease the costs and time to market [15]. These characteristics are particularly important in a scenario in which the client requires different variants of products, tailored to its specific needs [1] [16].

One of the biggest challenges regarding the assembly process is the optimized matching between components to be assembled. In manufacturing environments, the components are produced based on nominal dimensions with an additional tolerance range according to the product specification. As result of the manufacturing process, the produced components have real dimensions [17], that may be optimally combined for assembly. 
That situation is caused by dimensional variability propagation in every manufacturing process within the production system. It may create compliance difficulties such as slack differences involving the assembly of different components [18].

These differences include imperfections in the measurement instruments and machines, material deformation and operation flaws. Thus, it is necessary to determine and establish deviations within which the parts produced can still operate and function properly.

Those deviations constitute the upper and lower mechanical tolerance of a measurement or dimension. It is expected that, given a statistical margin, the parts produced have dimensions according to their nominal size considering the tolerance interval [19]. However, the tolerance interval is not the only factor to be considered for the best matching of components [1].

The material analysis may also be considered when treating the tolerance domains. Different methods of production and assembly of components must take the material's behavior into consideration. Stress and strength analyses can be used to observe effects of geometry, orientation, and thickness, so that it may be possible to determine types of adjustment and tolerance intervals [20].

To provide an optimal global tolerance of the assembly components, selective assembly selects a better mating pair by measuring, marking, and pairing the components accordingly [21]. However, the selective assembly continues to be a manual process. In this case, the automation of the assembly line is related to assembly itself, not to the selection of components.

As product variety increases in more customizable production systems, assembly methods and systems should be designed to handle such variety [6]. The complexity of those assembly processes increases with the demand of different variants, since the matching of components depends not only on tolerance intervals, but also on the part characteristics and specification.

Nerakae, Uangpairoj, and Chamniprasart [21] propose the use of machine vision to for selecting different components on an assembly line, representing initial efforts on automatic selection of different parts. However, it does not considers the best pairing between the components. Smart Assembly is being considered to promote an automatic selective assembly in the context of industrie 4.0 [22].

\subsection{Smart Assembly}

"Smart Assembly is the incorporation of learning, reconfigurability, humanmachine collaboration, and model-based techniques into assembly systems to improve productivity, cost, flexibility, responsiveness and quality" [23].

The development of "Smart Assembly" (SA) brings changes to the current assembly processes by re-inventing both its engineering and operations, considering the new technological and information environments of the manufacturers. In recent years, the further development of Industrie 4.0 promoted the technology required for Smart Assembly. 
SA goes far beyond traditional mechanization and automation to exploit the effective collaboration of man and machine in engineering and operations. It integrates highly skilled, multidisciplinary work teams with self-integrating and adaptive assembly processes. It unifies "virtual" and "real-time" information to achieve dramatic improvements in productivity, lead-time, agility, and quality. The vision for Smart Assembly is a system consisting of the optimal balance of people and automation interacting effectively, efficiently, and safely [24].

Therefore, a Smart Assembly system relies on its following characteristics [24]:

- Empowered, and knowledgeable people: skilled and enabled workforce to take the best overall decisions;

- Collaboration: between people and automation;

- Configurable: easy to reconfigure and reprogram the system due to changes in products, equipment, and software;

- Model and data driven: feasibility of modeling and simulating changes and actions virtually to evaluate, optimize and validate before definitive/costly implementations;

- Capable of learning: prevent repeated mistakes and avoid new ones.

Linked to the previous characteristics, there are some technological requirements to enable a successful Smart Assembly system: intelligent flexible assembly processes, equipment, and tools; an accurate, easy-to-use, persuasive, and persistent virtual capability; real-time actionable information for man and machine. In other words, these requirements focus mainly on multi-functionality, effectiveness, and reliability of the new technologies. Furthermore, the main challenge of the development of Smart Assembly is not the required enabling technologies themselves, but rather the integration of technologies.

The design of Smart Assembly processes, from the equipment and tools perspective, is simplified by adopting modular and multifunctional assembly components, i.e. components that have a specific or a combined set of functionalities that can be easily attached or detached to the project, with quick identification of consequences of the modifications on the other modules. The modularity grants to the Smart Assembly process flexibility and possibility of incremental and regular upgrades and updates (modularity is needed, given the common changes to manufacturing due to Industrie 4.0). It appeals to iterations of enhancement, learning, and adaptations, providing substantial and constant benefits related to the quality, effectiveness, and efficiency of products and processes.

Strang and Anderl [25] propose an Assembly Data Model to manage the large amount of data that is generated during the Smart Assembly. This model is composed of five work packages: Assembly Process Data, Product Data, Resources Data, Organization Data, and Deviation Management. It proposes the exchange of information between the assembly station and one component to be assembled, and clusters the information based on activities.

Therefore, the Assembly Data Model is associated with the Component Data Model and a new combination of information is stored for the assembly process [25]. 
The model proposed by Strang and Anderl [25] does not consider the best mating components, leaving space for improvements at the clustering of information and mating analysis.

\section{Methodology}

The applied research approach is based on designing, implementing, and testing a Smart Assembly scenario. Besides, a literature review was conducted to define the preliminary requirements for Smart Assembly. The scenario simulates the application of Industrie 4.0 concepts and technologies for communication. The focus of the broad research is in the data model requirements for Smart Assembly. This paper focuses on the creation of a preliminary data model for Smart Assembly. Two different scenarios were implemented and simulated: a regular assembly process; and a Smart Assembly process.

The scenario was implemented at the Technical University of Darmstadt (TUD), Germany, the University of São Paulo (USP) and the Methodist University of Piracicaba (UNIMEP), Brazil. The scenario implementation is part of a broader research project within the research collaboration framework in manufacturing called BRAGECRIM (Brazilian-German Collaborative Research Initiative in Manufacturing).

The scenario focuses on the production of a pneumatic cylinder. The pneumatic cylinder is composed of two parts, produced separately. This part is a standard item already used at the Center for Industrial Productivity (CiP) located at TUD. Simplifications were made to the model to facilitate production with the equipment available and to cope with intellectual property requirements, as the part used at CiP is real.

Through those scenarios, it is possible to gather the advantages and disadvantages of each assembly alternative. The comparison is made between the "regular assembly" model, which refers to a system that would be utilized nowadays and the "Smart Assembly" model, which would be theoretically implemented in a smart factory that follows the vision of Industrie 4.0.

In the first scenario (Fig. 1), the central factory located at TUD in Germany sends the production order to both factories in Brazil (Site 1 and Site 2). The manufacturing process begins and is monitored by the central factory. After the parts are produced, they go through quality control, which indicates if the part is suitable for use. It is important to notice that in this model, the central factory has no control over the quality inspection.

Afterwards, the parts from Site 2 are shipped to Site 1, where the assembly is held and feedback is sent to Germany. When successful, the assembled product may be forwarded and shipped to customers. 


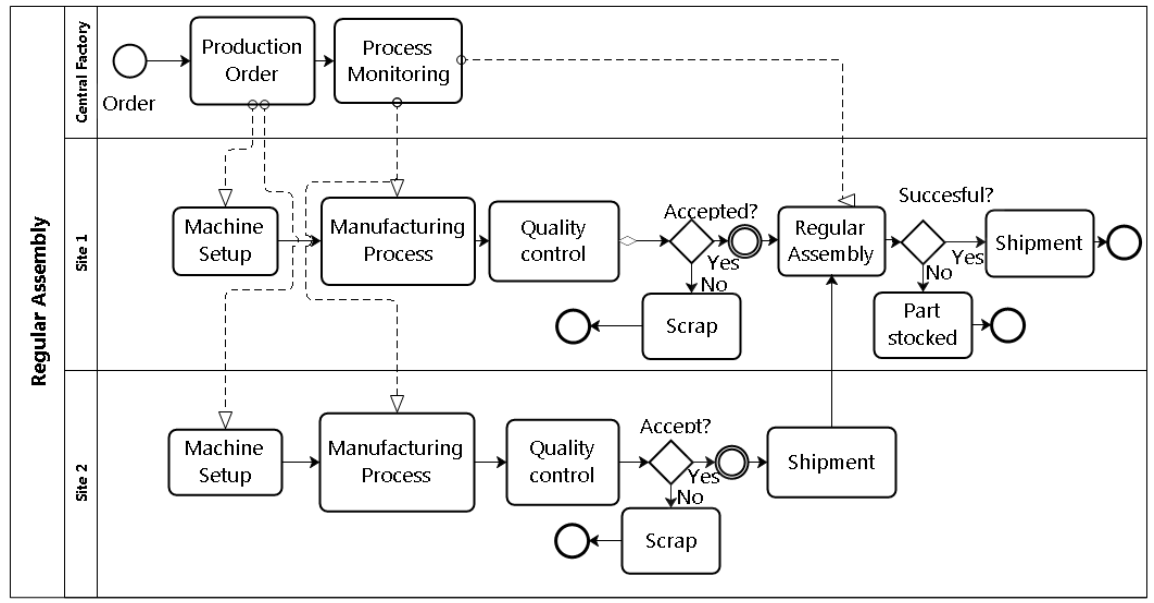

Fig. 1. Scenario 1 - Regular Assembly

In the second scenario (Fig. 2), the German central factory sends the production order to the factories in Brazil. Then the manufacturing processes is triggered (Site 1 and Site 2). After parts are produced, they go through a precise measurement and registration system, which send all the information to the central factory. The relevant aspect here is that the quality control fulfillment is held remotely in the central factory (in Germany), giving full control to the central factory over which parts should be accepted and which should be discarded or remanufactured.

After the quality inspection, the information is sent back to Brazil, indicating which parts should be forwarded to the assembly process. The parts from Site 2 are then shipped to Site 1 where the Smart Assembly takes place. Finally, the assembled products are shipped to the customers.

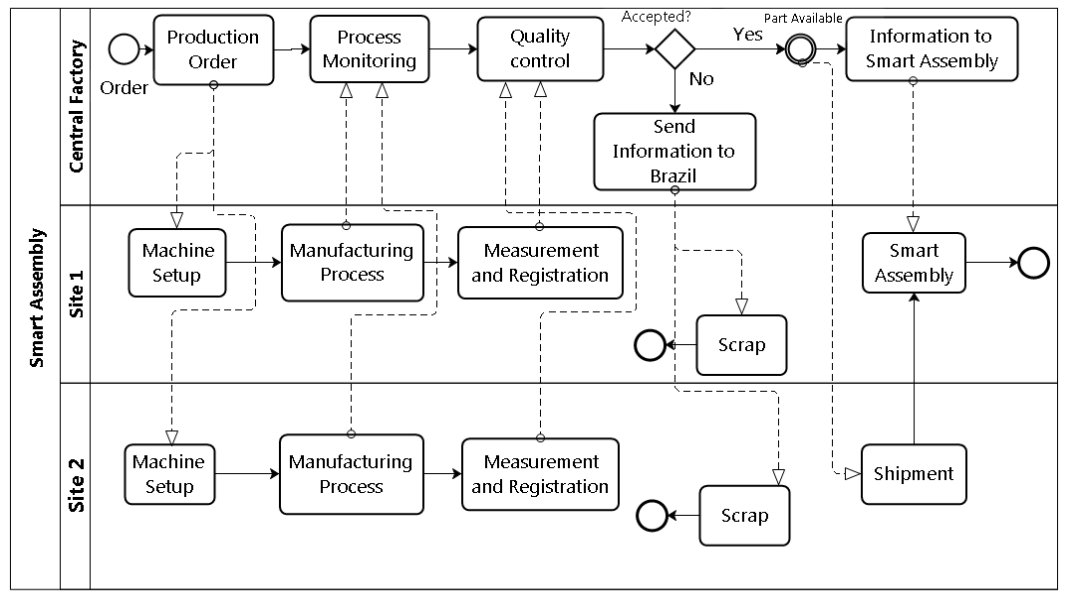

Fig. 2. Scenario 2 - Smart Assembly 
The development of those scenarios provided context and requirements for the development of a preliminary data model for Smart Assembly.

\section{Preliminary Data Model}

Based on the literature review, requirements for Smart Assembly were identified. Table 1 presents the requirements, the type of the requirement, and the requirement's source.

Requirement types are: Specification - related to the nominal characteristics of the product as nominal dimensions, material, equipments and machines; Order - related to the clients' specific information; and Process - related to the manufacturing characteristics [1].

Table 1: Requirements for Smart Assembly

\begin{tabular}{ccc}
\hline Requirement & Type & Source \\
\hline Material information & Specification & {$[18]$} \\
Equipments and machines & Specification & {$[18]$} \\
Tolerance & Specification & {$[19]$} \\
Variant information & Order & {$[1]$} \\
Unique identification & Order & {$[26]$} \\
Real-time information & Process & {$[24]$} \\
Flexibility & Process & {$[22]$} \\
Capable of learning & Process & {$[24]$} \\
\hline
\end{tabular}

Based on the literature review and on the simulation, it is possible to design a preliminary data model for a Smart Assembly process. A data model for Smart Assembly process must contain a unique identification for every component, the geometric information of the component, and tolerance information. It must be able to exchange information with other components and process this information to ensure the correct and best matching of the components. Thus, a data model for Smart Assembly is an integrated component data model, as proposed by Picard and Anderl [1], with the addition of a new work package for exchange and receiving data from different components, and processing this information for ensuring the best matching of components.

Considering the requirements gathered, the model proposed by Picard and Anderl [1] is extended to a preliminary Data Model for Smart Assembly as presented in Fig. 3. Combining different information on a new work package. The data model is organized into six work packages: the Core Model, that handles basic administrative tasks and also provides an extension interface for the additional work packages: Order-related Data, Rights Management Data, Production Data, Identification \& Specifications Data, and Assembly Data. 


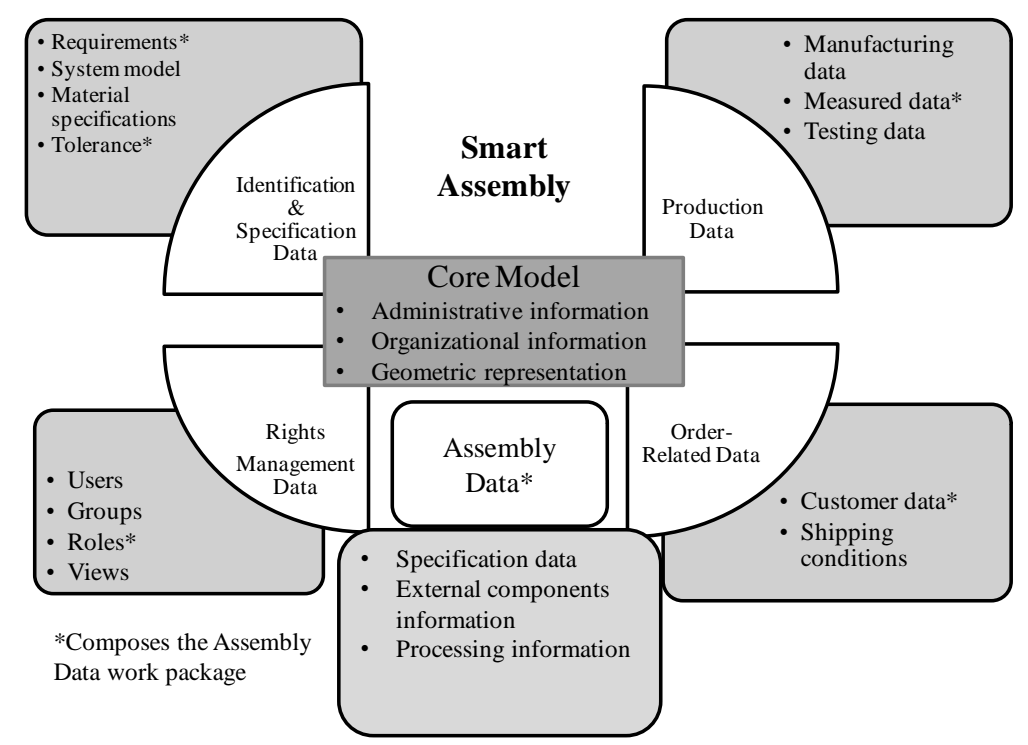

Fig. 3: Data Model - Smart Assembly - Adapted from [1]

Thus, a Smart Assembly data model is composed by its Identification and Specifications Data, Production Data, Rights Management Data, Order-Related Data, and Assembly Data. All work packages are connected by an identification number as a primary key (core) to connect information over the assembly model.

Identification and Specification carries the requirements of the components itself and of the whole product, leading to the next steps of the assembly process. This enables traceability of the component's production history and allows the optimization of future products and production processes [27]. Besides, it carries the tolerance information, used for a mating analysis.

The Order-Related Data captures customer-specific requests and, therefore, enables customized production of components within a smart production environment. For a smart assembly process, the Order-Related Data is important for providing different combinations of components, according to customer request. It becomes the primary assembly criteria, matching the different components of the same customer. Besides, it provides the shipping information.

The information contained at this two proposed work packages (Identification \& Specification Data and Order-Related Data) are inserted both at Product Data and Process Data in the model suggested by Strang and Anderl [25], which clusters the data by the type of activity (assembly or manufacturing, for example). This type of clustering increases the complexity of data storage once that the activity becomes a primary key over the type of information.

Production Data capture the characteristics of the specific component with data originating from manufacturing execution systems (MES). Process data such as responsible worker, utilized machines, workstations, and tools together with testing data, such as measurements, are captured to constitute actual production activities. This information is associated with the Resources Data suggested by Strang and Anderl [25], once they carry the machines and workforce that are required for the assembly process.

To ensure that only authorized parties can access and modify the data, the Rights Management Data tracks all user (human users and smart systems) and user groups (departments, organizations, etc.) of component data together with their respective privileges, what is directly associated with Organization Data suggested by Strang and Anderl [25]. 
Finally, the Assembly Data work package is responsible for the communication between the component that is to be assembled and the component that is to be received. It is responsible for indicating the best match between two different components considering the product tolerance, the product material, the client specification, and the needed assembly. This work package improves the model proposed by Strang and Anderl [25], as it enables an intelligent matching process.

The Assembly Data work package collects the ID information from the part to be assembled via RFID or QRCode. This information is a primary key and it is used to track the part. Afterwards, the system searches for the specifications of that part, storing the actual dimension and the mating component.. Once it is known which part to search for, both for the Order-Related Data and for Identification \& Specification Data, the system searches for different parts of the required type. Each part is submitted to a $360^{\circ}$ image analysis, allowing the part to be compared with the customer data and requirements, producing a best matching according to two criteria: first, Order-Related data, and second, an automatic selective assembly process. The Assembly Model compares the optimized matching sending this information back to the component data model, providing the best fit in an efficient way. Besides, considering that the model possess all different measures from the mating components, the best combination is automatically calculated during the process, decreasing re-manufacturing needs, once that the remaining measures are known.

Fig. 4 brings in detail the Assembly Data work package represented by an UML diagram. UML models provide stereotypes and constraints, together with syntax and semantics of the elements [28].

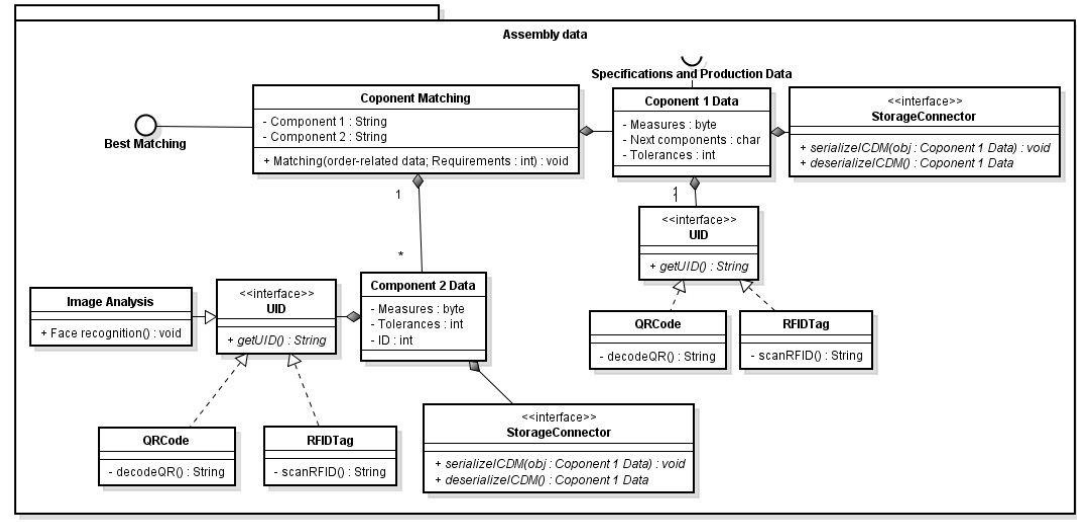

Fig. 4. Smart Assembly

It is important to highlight that the Assembly Data work package is fast responsive and provides real-time information indicating the part to be assembled and the best 
mating components, automating a selective assembly process. Besides, it can be adapted according to clients' specification, considering that the Order-Related Data is one of the prior matching characteristic. Therefore, instead of having an assembly model containing a Component Data Model, the proposed model is a combination of the Component Data Model and the assembly specific data, clustering the data based on the type of information. This supports a more accurate traceability, going from the type of information to the activity, not the other way around. Also, it improves the global tolerance by automatically selecting the best mating components.

\section{Conclusions}

The research initiative Industrie 4.0 aims to be a driving force of the $4^{\text {th }}$ Industrial Revolution. Its purpose is to create an intelligent production chain connecting the physical product with data collected over the product lifecycle and turning this data into information. Each client provides unique information so that the product can be tailored to its requirements, challenging the assumptions of traditional mass production. A major issue for industry is to offer customized products without substantial impact on final costs at both the manufacturing and distribution of the products [2]. Therefore, new approaches and solutions are required for manufacturing and assembly.

The assembly process is one of the most relevant steps to high product variety. A Smart Assembly Data Model aims to create a representation of the communication between the component and its surrounding environment over its entire lifecycle. It contains a unique identification for every component, the geometric information of the component, tolerance information. It must also be able to exchange information with other components and process this information to ensure the correct and best matching of the components.

This paper represents the initial effort on the development of a Smart Assembly Data Model within the collaborative research project "Smart Components within Smart Production Processes and Environments - SCoPE" supported by the BRAGECRIM Program. It improves previous assembly models by considering an automatic selection of the best mating pairs and clustering data by the type of information. Next steps in this research stream include further development of the Smart Assembly Data Model, prototypical implementation, and advanced scenario testing.

\section{Acknowledgments}

The authors thank the Coordination for the Improvement of Higher Education Personnel (Capes), the Brazilian National Council for Scientific and Technological Development (CNPq), and the German Research Foundation (DFG) for supporting related projects. The authors also thank the companies involved for providing real case applications. 


\section{References}

1. A. Piccard and R. Anderl, "Integrated Component Data Model for Smart Production Planning," in $19^{\circ}$ Seminário Internacional de Alta Tecnologia, 2014.

2. H. ElMaraghy, G. Schuh, W. Elmaraghy, F. Piller, P. Schönsleben, M. Tseng, and a. Bernard, "Product variety management," CIRP Ann. - Manuf. Technol., vol. 62, pp. 629652, 2013.

3. F. Salvador, P. M. De Holan, and F. Piller, "Cracking the Code of Mass Customization | MIT Sloan Management Review,” MIT Sloan Manag. Rev., no. 50315, 2009.

4. P. Zipkin, "The Limits of Mass Customization.," MIT Sloan Manag. Rev., vol. 42, pp. 17, 2001.

5. F. Salvador, C. . Forza, and M. . Rungtusanatham, "Modularity, product variety, production volume, and component sourcing: Theorizing beyond generic prescriptions," J. Oper. Manag., vol. 20, pp. 549-575, 2002.

6. S. J. Hu, J. Ko, L. Weyand, H. A. Elmaraghy, T. K. Lien, Y. Koren, H. Bley, G. Chryssolouris, N. Nasr, and M. Shpitalni, "Assembly system design and operations for product variety," CIRP Ann. - Manuf. Technol., vol. 60, no. 2, pp. 715-733, 2011.

7. H. ElMaraghy and W. ElMaraghy, "Smart Adaptable Assembly Systems," Procedia CIRP, vol. 44, pp. 4-13, 2016.

8. H. Kagermann, W. Wahlster, and J. Helbig, "Recommendations for implementing the strategic initiative INDUSTRIE 4.0,” Final Rep. Ind. 4.0 WG, no. April, p. 82, 2013.

9. E. Hobsbawn, The Age of Revolution, vol. 39. 1961.

10. S. Ariss, T. Raghunathan, and A. Kunnathar, "Factors affecting the adoption of advanced manufacturing technology in small firms," S.A.M. Adv. Manag. J., 2000.

11. H. Sun, "Current and future patterns of using advanced manufacturing technologies," Technovation, 2000.

12. K. Boyer and M. Pagell, "Measurement issues in empirical research: improving methods of operations strategy and advanced manufacturing technology," J. Oper. Manag., vol. 18, 2000.

13. S. Kotha, "Strategy, manufacturing structure and advancedmanufacturing technology," in National Conference of the Academy of Management, 1991.

14. Y. Koren and M. Shpitalni, "Design of reconfigurable manufacturing systems," J. Manuf. Syst., vol. 29, no. 4, pp. 130-141, 2010.

15. H. P. Wang and J. K. Li, Computer-aided process planning. North Holland: Elsevier, 1991.

16. K.-D. V.-L. Nguyen, Minh-Tu, Hai-Khanh Nguyen, "Virtual, Augmented and Mixed Reality," 5th Int. Conf. VAMR 2013, Held as Part HCI Int. 2013, vol. 8021, p. 399, 2013.

17. R. K. Rajput, A Textbook of Manufacturing Technology (Manufacturing Processes). New Delhi: Laxmi Publications, 2007.

18. J. Camelio, S. J. Hu, and D. Ceglarek, "Modeling variation propagation of multi-station assembly systems with compliant parts," J. Mech. Des., vol. 125, no. December 2003, pp. 673-681, 2003.

19. H. S. Seo and B. M. Kwak, "Efficient statistical tolerance analysis for general distributions using three-point information," Int. J. Prod. Res., vol. 40, no. 4, pp. 931-944, 2002.

20. P. P. Camanho and F. L. Matthews, "Stress analysis and strength prediction of mechanically fastened joints in FRP: a review," Compos. Part A Appl. Sci. Manuf., vol. 28, no. 6, pp. 529-547, 1997.

21. Y. Zhang, Y. Yin, and M. Yang, "A new selective assembly approach for remanufacturing of mating parts," 40th Int. Conf. Comput. Ind. Eng. Soft Comput. Tech. Adv. Manuf. Serv. Syst. CIE40 2010, 2010. 
22. M. Liu, J. Ma, L. Lin, M. Ge, Q. Wang, and C. Liu, "Intelligent assembly system for mechanical products and key technology based on internet of things," J. Intell. Manuf., 2014.

23. IMTI - NIST, “A Report on Smart Assembly," 2006.

24. J. A. Slotwinski and R. B. Tilove, "Smart assembly: Industry needs and challenges," Perform. Metrics Intell. Syst. Work., no. c, pp. 271-276, 2007.

25. D. Strang and R. Anderl, "Assembly Process driven Component Data Model in CyberPhysical Production Systems," in World Congress on Engineering and Computer Science, 2014, vol. II, pp. 22-24.

26. S. Takata, F. Kimura, F. J. a M. Van Houten, and E. Westkämper, "Maintenance: Changing Role in Life Cycle Management," CIRP Ann. - Manuf. Technol., vol. 53, no. 2, pp. 643-655, 2004.

27. L. F. C. S. Durao, H. Eichhorn, R. Anderl, K. Schuetzer, and E. Zancul, "Integrated Component Data Model Based on UML for Smart Components Lifecycle Management: A Conceptual Approach," IFIP Adv. Inf. Commun. Technol., vol. 467, pp. 13-22, 2015.

28. X. Tang and H. Yun, "Data model for quality in product lifecycle," Comput. Ind., vol. 59, no. $2-3$, pp. $167-179,2008$. 